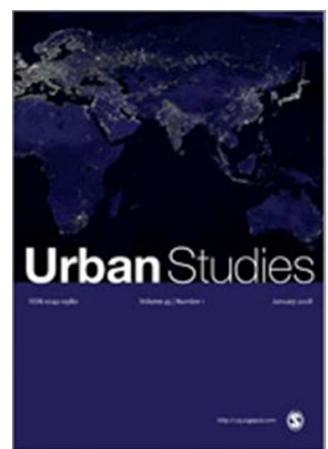

\title{
New Urban Worlds: Inhabiting Dissonant Times
}

\begin{tabular}{|r|l|}
\hline Journal: & Urban Studies \\
\hline Manuscript ID & CUS-279-18-03 \\
\hline Manuscript Type: & Book Review \\
\hline <b> Discipline: Please select a \\
keyword from the following list \\
that best describes the \\
discipline used in your paper.:
\end{tabular}

\section{SCHOLARONE}

Manuscripts 
Simone, AM and Pieterse E, New Urban Worlds: Inhabiting Dissonant Times, Polity: Cambridge, 2017; 247 pp.: 978-0-745-69156-5, £16.99 / US\$24.95 (pbk)

Reviewed by: William Monteith, School of Geography, Queen Mary University of London

Every now and again, the emperor must be disrobed. Disciplinary debates - shaped by the clothes of a thousand emperors past - become stale, and detached from the empirical realities they purport to describe. Over the past two decades, AbdouMaliq Simone, among a number of poststructural scholars, has dutifully disrobed the field of urban studies, preparing the ground for a new vocabulary of urbanism that is better able to convey the dissonant realities of emerging city life in the global South. Gone are the confident and well-worn concepts of 'gentrification', 'renewal', 'entrepreneurialism', and 'public space'. In their place stand an array of challenging and often indeterminate notions, including those of 'secretion', 'resonance' and 're-description', which reflect the unfolding paradoxes of urban life in the majority world.

In New Urban Worlds, Simone is reunited with Edgar Pieterse, a long-term collaborator in the project to shift the epistemological horizons of urban studies to the South. Their work, along with that of Roy and Ong (2011) and Amin and Thrift (2016), contributes to a growing body of relational literature on cities that rejects the existence of any single 'overarching theoretical story' about urbanization (p. 185). This literature identifies a disconnect between the convictions of the urban studies scholarship, and the uncertainties of urban life across much of the world. In a field that has long been drawn to what is fixed, dominant and continuous, these authors are instead drawn to phenomena that 'leak from the frame' (p.94). What aspects of urban life go uncaptured by dominant theories; for example, of governance and capital? What is the 'surplus' that remains after conventional (northern) frameworks have been applied? And how might this surplus form the basis of alternative, generative theories of urban life that are understandable to a diverse range of actors? These are important and timely questions.

Simone and Pieterse suggest two points of departure: i) to abandon the 'disciplinary and thematic stories that weigh urban studies down' (p.197), and ii) to restore experimentation 'as a normative aspect of living in and running cities' (p. $x$ ). This approach requires a willingness to work with the details of how urban inhabitants, institutions and technologies operate 'without necessarily rushing to envelop the details in ready-made ideological or interpretive 
frameworks' (p. xviii). The authors illustrate this approach by distilling their long-term engagements with cities in sub-Saharan Africa and Southeast Asia into a number of 'conceptual interventions' that foreground the agentive struggles of urban inhabitants (p. 10). These include the notions of 'resonance', which emphasises the connectivity of different people and places, 'secretion', which invokes the porosity of predominant forms of power; and 're-description', which foregrounds the capacity of observers to imagine alternative visions of urban life.

The conceptual work done by terms such as 'resonance' and 'secretion' will be familiar to scholars conversant with theories of assemblage (McFarlane 2011) and everyday resistance (Scott 1985). Nevertheless, they are invoked here in ways that breathe new life into urban studies, by centring the insurgent, the makeshift and the provisional, chipping away at teleological theories of urbanization.

Re-description is what the book does best. Familiar objects of study are often re-described in ways that sidestep sterile debates and open up new lines of enquiry. For example, rather than objects of governance or capital, urban markets are depicted as 'story-making machines' (p.185) that are understood as dangerous places insofar as they unsettle the dominance of any single story (p.92). Markets therefore provide important contexts for 'witnessing how economic and social realities get 'done" amid a backdrop of simplifying and often deceptive narratives (p.89). There is a critical methodological implication here. Given the limited infiltration of standardised models of governance and economy in many cities in the global South, a methodological reliance on associated instruments, such as elite interviews and micro-economic surveys, is likely to result in a simplistic and misleading representation of urban life. If you want to understand how a city works, spend some time in the market.

The vision of urban life that emerges here is messy, pluralistic, paradoxical and - perhaps above all - serendipitous. Simone and Pieterse call on researchers to be as experimental and eclectic in our scholarship as urban inhabitants are in their everyday lives; borrowing ideas and resources from different domains, and re-assembling them in ways that shed new light on pressing issues. I am in full support of this project. Nevertheless, there is need to be more explicit about its means and limitations in order for it to 'add up' to more than the sum of its parts; in other words, for it to provide a solid epistemological grounding on which other researchers are able to contribute. In this spirit, I identify three areas in need of clarification and expansion. 
Secondly and relatedly, for a book committed to working with the 'details' of urban life, there is a notable lack of empirical illustration. Analyses often take place at the level of 'urban Africa' and 'Asia', with occasional departures to Jakarta, Kinshasa and Cape Town. As a result, the cities of these two giant regions of the world tend to fold into one another, unchallenged by differences of culture, politics or economy. To a certain extent, this lack of empirical depth is an inevitable consequence of the book's ambitious breadth. However, it also undermines the argument at times; for example, in the absence of the subjective accounts of urban inhabitants, the book arguably reproduces rather than resists 'a politics of urban knowledge [in which] the 'majority' has been ordered to 'shut up', (p. xiii).

Thirdly and finally, while the authors are rightly suspicious of the dominance of 'stories' in urban studies that derive from the historical experiences of (post-)industrial cities in the global North, they need not do away with all structural analysis. Although urban life in much of the global South involves a great deal of experimentation, this experimentation usually takes place within a social and cultural space that places limits on what can be negotiated with who. Furthermore, it is it possible to observe the impact of such structures without enveloping them in 'ready-made' ideological frameworks, or labelling them as paradigmatic of a 'Southern' urbanism. For example, James Ferguson (2015) has recently argued that the livelihood activities of young men and women in cities in Southern Africa adhere to logics of (re)distribution and reciprocal obligation that have a long history in the region. In the absence 
of cultural and historical analysis, there is a danger of representing the inhabitants of "new urban worlds' as one and the same; as 'experimenters' without borders or pressing personal concerns.

Scholars of a structural persuasion are likely to be frustrated by these omissions. However, there is much that is worth grappling with here. By purposefully 'disrobing' the field of urban studies, Simone and Pieterse contribute to its survival as a responsive and a pluralistic intellectual space.

\section{References}

Amin A and Thrift N (2016) Seeing Like a City, Cambridge: Polity Press

Ferguson J (2015) Give a Man a Fish: Reflections on the New Politics of Distribution, Durham and London: Duke University Press

McFarlane C (2011) Assemblage and critical urbanism, City 15(2), pp. 204-224.

Roy A and Ong (2011) Worlding Cities: Asian Experiments and the Art of Being Global, London: Wiley-Blackwell

Scott J (1985) Weapons of the Weak: Everyday Forms of Peasant Resistance, London: Yale University Press 